\title{
Non-Protein Calorie: Nitrogen Ratio (NPC/N) as an Indicator of Nitrogen Balance in Clinical Settings
}

\author{
Teruyoshi Amagai*1, Mari Hasegawa ${ }^{1}$, Moeko Kitagawa ${ }^{2}$ and Seiji Haji ${ }^{3}$ \\ ${ }^{1}$ Department of Food Sciences and Nutrition, Mukogawa Women's University, Japan \\ ${ }^{2}$ Department of Clinical Nutrition, Kitano Hospital, Japan \\ ${ }^{3}$ Department of Surgery, Takarazuka Iso Hospital, Japan
}

Received: June 19, 2018; Published: June 25, 2018

*Corresponding author: Teruyoshi Amagai, Department of Food Sciences and Nutrition, Japan

\begin{abstract}
Background: An energy and protein provision to patients in clinical settings, with not only acute but non-acute illnesses, have been reported an essential to prevent body mass wasting if they are provided sufficiently. A malnutrition observed in acute and chronic illnesses is more or less resulted from an inflammation.
\end{abstract}

Methods: We set three clinical questions to analyze:

a) To which extents is protein provision sufficient to prevent adverse events in nutritional management,

b) Is there any relevant indicator to prevent muscle loss,

c) If it exists, is there any explanation to make clear the mechanism hidden behind it?

Results :

a) 1.2-1.5 gram protein per kg of preadmission body weight was defined optimal target.

b) There was a significant relation between total protein loss and calorie: $\mathrm{N}$ ratio. Additionally, non-protein calorie: $\mathrm{N}(\mathrm{NPC} / \mathrm{N})$ ratio were also proposed as indicators of $\mathrm{N}$ balance in the literatures.

c) The hormonal and metabolic reactions to starvation and stress were studied to ensure the mechanism hidden behind these sequences.

Conclusion: From the review of the literatures, we would propose NPC/N ratio as a clinically feasible indicator of nitrogen balance to prevent muscle loss or adverse events to prevent in patients with acute and non-acute illnesses.

Keywords: Non-Protein Calorie: Nitrogen Ratio; NPC/N; Nutrition Management

\section{Introduction}

An energy and protein provision to patients in clinical settings, not only in acute but in non-acute, have been reported essential to prevent body mass losing if provided sufficiently [1]. A malnutrition still frequently observed in acute and chronic illnesses could be identical, more or less, to an inflammation observed as main cause of malnutrition [2]. Under inflammatory circumstances, pro-inflammatory cytokine storm on skeletal muscles insults on muscle to result in loss of muscle mass and cachexic sequences occurs [3]. In these contexts, insufficient energy and protein managements in patients with acute or non-acute illnesses have been reported to have an impact on morbidity and mortality [4-6]. In other words, an appropriate nutritional management with sufficient energy and protein might prevent muscle loss and poor outcome.

\section{Methods}

From these nutritional points of view, three key questions are raised to analyze:

a) To which extents is protein provision sufficient to prevent adverse events in nutritional management,

b) Is there any relevant indicator to prevent muscle loss, and

c) If it exists, is there any explanation to make clear the 
mechanism hidden behind it? To answer to these three clinical questions (CQs), we reviewed the literatures.

\section{Results}

\section{CQ 1: To which extents is protein Provision sufficient?}

The Dutch Perioperative Guideline in 2007 [7] has proposed that 1.2 -1.5gram protein per kg of preadmission body weight was defined optimal target followed by several additional clinical studies in critically ill settings[4-6].

\section{CQ 2: Is there any relevant indicator to prevent muscle loss?}

A systematic review successfully identified in 53 studies with 91 cohorts which comprised 1107 subjects that a significant relation between total protein loss, expressed in nitrogen $(\mathrm{N})$ weight (g), and energy (E) to N provision (E/N) [8]. Moving back to early 1980 's, however, similar idea of calorie: $\mathrm{N}$ ratio calculated in infu- sion formulae has already been proposed as a relevant indicator of $\mathrm{N}$ balance (NPC/N: kcal/gram in its unit) in patients after burn [9]. In this article, the authors emphasized clinical importance of non-protein calorie: $\mathrm{N}$ ratio. To our knowledge, this is the first paper to propose to utilize this ratio in the clinical setting. An energy was expressed in infused in this article, whereas the energy expenditure was in the former article. From aspect of clinical simplicity, the actually $\mathrm{E}$ intake seems more feasible than measured energy expenditure. Comparing administered $\mathrm{E} / \mathrm{N}$ with $\mathrm{NPC} / \mathrm{N}$, as NPC/N is transferable to an equation of $\left[6.25^{*}(\mathrm{E} / \mathrm{N})-25\right]$ mathematically, these two parameters must be identical. In these reasons, we would re-propose NPC/N ratio, ranging from 125 to 225 for less stressed patients (Figure 1), as a relevant indicator of $\mathrm{N}$ balance in clinical settings. In this figure, areas of NPC/N under 125 or over 225 indicate that for protein restriction such as in chronic kidney diseases, or for protein loading in post-stress status, respectively.

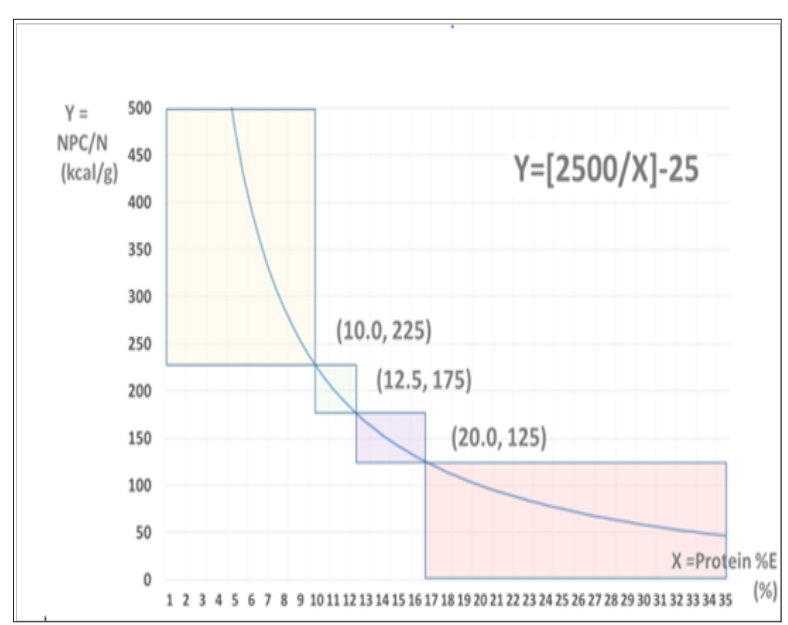

Figure 1: Relationship between protein dose in total energy (\%) and non-protein calorie: nitrogen ratio (NPC/N). This relationship is shown in fractional function in mathematical manner. Here, the fractional function is shown: $Y=2500 / X-25$. $\mathrm{NPC} / \mathrm{N}$ is ranging from 125 to 225 for ordinary conditions. To contrary, areas of NPC/N under 125 or over 225 indicate that for protein restriction such as in chronic kidney diseases, or for protein loading in post-stress status, respectively. The coordinates of three points exist at borders among three areas mentioned above are the follows: $(10.0,225),(12.5,175)$, and $(20.0,125)$ from left to right direction in $\mathrm{x}$-axis.

\section{CQ 3: Is there any explanation to make clear the mecha- nism hidden behind it?}

Around 1980's, nutritional managements in patients under surgical stress have vigorously studied to prevent negative $\mathrm{N}$ balance and adverse events. Among these studies, the article written by group of Francis D Moore has clearly proved hormonal stabilities, mainly using insulin and insulin/glucagon ratios, provided by sufficient amount of energy to prevent ketogenic reactions observed in starvations $[10,11]$. In their observations, additional observations to administrate high dose carbohydrate were related with significantly high serum insulin and low ketone body production, both reflecting preventions of amino acids moving from skeletal muscles and diminishments of gluconeogenesis. Both has been identified to inhibit catabolic reactions to prevent protein energy malnutrition and poor clinical outcomes.

\section{Conclusion}

From the review of the literatures, we would propose NPC/N ratio as a clinically feasible indicator of nitrogen balance in patients with acute and non-acute illness [3].

\section{References}

1. Weijs PJ, Wischmeyer PE (2013) Optimizing energy and protein balance in the ICU. Curr Opin Clin Nutr Metab Care 16(2): 194-201.

2. Cederholm T, Jensen GL (2017) To create a consensus on malnutrition diagnostic criteria: A report from the Global Leadership Initiative on Malnutrition (GLIM) meeting at the ESPEN Congress 2016. Clin Nutr 36(1): 7-10.

3. Kitagawa M, Haji S, Amagai T (2017) High Serum Essential Amino Acids as a Predictor of SkeletalMuscle Depletion in Patients With Cachexia and Advanced Gastrointestinal Cancers. Nutr Clin Pract 32(5): 645-651.

4. Alberda C, Gramlich L, Jones N, Jeejeebhoy K, Day AG, et al. (2009) The relationship betweenutritonal intake and clinical outcomes in critically 
ill patients: results of an international multicenter observational study. Intensive Care Med 35(10): 1728-1737.

5. Weijs PJ, Stapel SN, De Groot SD, Driessen RH, De Jong E, et al. (2012) Optimal protein and energy nutrition decreases mortality in mechanically ventilated, critically ill patients: a prospective observational cohort study. JPEN J parenter Enteral Nutr 36(1): 60-68.

6. Allingstrup MJ, Esmailzaden N, Wilkens Knudsen A, Espersen K, Hartvig Jensen T, et al. (2012) Provision of protein and energy in relation to measured requirements in intensive care patients. Clin Nutr 31: 462468.

7. Sauerwein HP, Strack Van Schindel RJ (2007) Perspective: how to evaluate syudies on peri-operative nutrition? Considerations about the definition of optimal nutriton for patients and its key role in the comparison of the results of studies on nutrtional intervention. Clin Nutr 26: $154-158$.

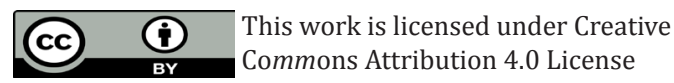

Submission Link: https://biomedres.us/submit-manuscript.php
8. Kreymann G, DeLegge MH, Luft G, Hise ME, Zaloga GP (2012) The ratio of energy expenditure to nitrogen loss in diverse patient groups--a systematic review. Clin Nutr 31(2): 168-175.

9. Matsuda T, Kagan RJ, Hanumadass M, Jonasson (1983) The importance of burn wound size in determining the optimal calorie:nitrogen ratio. Surgery 94(4): 562-568.

10. Wolfe BM, Culebras JM, Sim AJW, Ball MR, Moore FD, et al. (1977) Substrate interaction in intravenous feeding: Comparative effects of carbohydrate and fat on amino acid utilization in fasting man. Ann Surg 186(4): 518-540.

11. Tweedle DEF, Fitzpatrick GF, Brennan MF (1977) Intravenous amino acids as the sole nutritional substrate utilization and metabolism in fasting normal human subjects. Ann Surg 186(1): 60-73.

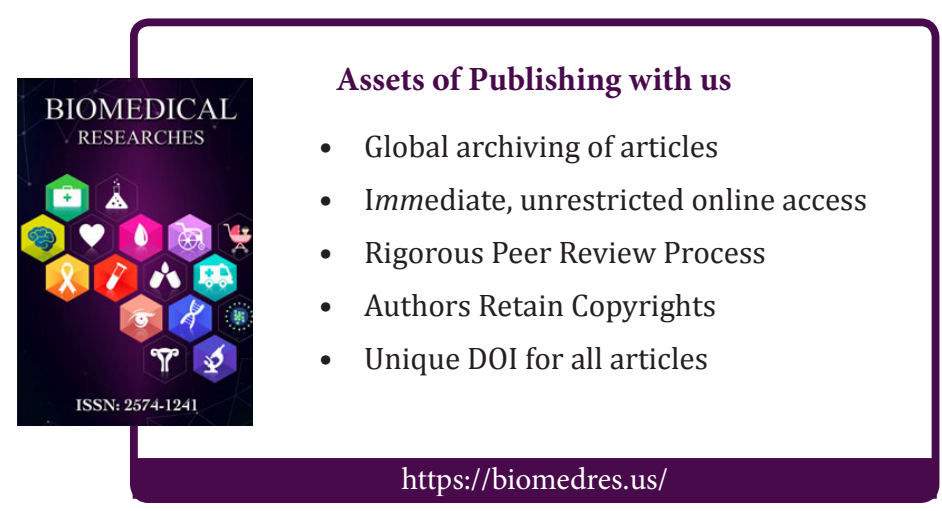

